Tetrahedron Letters, vol.27, No.49,pp 5981-5984,1986 Printed in Great Britain
$0040-4039 / 86 \$ 3.00+.00$

Pergamon Journals Ltd.

\title{
FREE RADICAL CARBOCYCLIC RING RECONSTRUCTION
}

\author{
Živorad Čeković* and Radomir Saičić \\ Department of Chemistry, Faculty of Sciences, University of BeIgrade, \\ Studentski trg 16, 11001 Belgrade, Yugoslavia
}

\begin{abstract}
Alkenyl radical generated by $\beta$-fragmentation of tertiary cyclohexyloxy radical with carbocvclic ring opening, possessing a suitably located olefinic double bond, undergoes to the intramolecular 5-exo-trigonal cyclization and a new carbocycljc ring was formed.
\end{abstract}

Among a varicty of reactions $\beta$-fragmentation is one of the preferential mode of stabilisation of tertiary alkoxy radicals ${ }^{2}$. Homopolar nature of $\beta-c l e a v a g e$ reaction of alkoxy radicals is well-sstablished and the carbonyl containing fragment and products derived trum the alkyl radical fragment were producedl-6. The rate of B-cleavage of alkoxy radicals is independent of the radical precursors but is mainly dependent of the stability of the initialy formed carbon radicals ${ }^{2}, 3$. Thereby, intramolecular cyclization of 5-hexenyl radicals to the cyclopentylmethyl radicals are well known reaction for the construction of carbocyclic ${ }^{\prime}$ and heterocyclic rings ${ }^{9}$.

However, homopolar scission of $\mathrm{C}-\mathrm{C}$ bond in the alkoxy radical intermediates, followed by radical recombination reaction with a new c-c bond formation in the same molecule have not been investigated together as a sequence of reactions. This radical recombination reactions could involve one ring opening and the other ring closure with a considerable change of the carbon skeleton (Scheme 1. ).
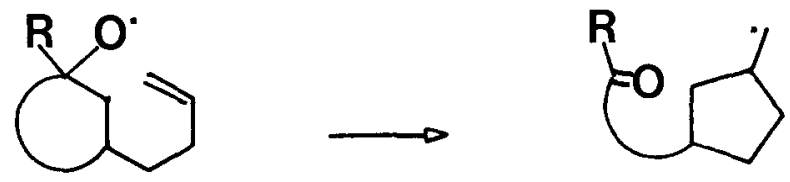

Scheme 1 .

We wish to report a new approach to a abocyclic ring reconstruction involving a tertiary alkoxy radical fragmentation and intramolecular addition of arising alkenyl radical onto the suitably located olefinic double bond.

It was found that this free radical fragmentation-cyclization reaction involving a ring reconstruction can be achieved by ferrous ion induced decomposition of l-alkyl-or l-aryl-3-(3-alkenyl)-cyclohexyl hydroperoxides la-clo. Two saturated ketones having a cyclopentane ring $23-\underline{a}$ and $3 a-c$ were obiained as a chief reaction products in $28-38 \%$ and $7-30 \%$ yields, respectively, in addition to the unsaturated ketones $4 \mathrm{a}-\mathrm{c} \quad(8-30 \%)$ and starting $01 \mathrm{cohols} 5 \mathrm{a}-\mathrm{c} \quad(7-20 \% \mathrm{yields})$ (scheme 2.). 
In a typical experiment $2.48 \mathrm{~g}$ ( 13.5 mmole) of alkyl hydroperoxide $\underline{a}^{11}$ was treated with $3.75 \mathrm{~g}$ of powdered crystaline ferrous sulfate in acetic. acid as a solvent in inert atmosphere. During $3 \mathrm{hrs}$ hydroperoxide was completly reduced. The reaction inixture was worked up as it was described ${ }^{12}$ and products were separated and purified by $\underline{g l c}$ and characterized by $\underline{i r}, \underline{n m r}$ and mass spectral ${ }^{13}$.

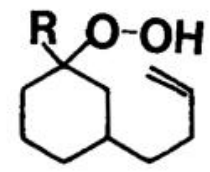

1

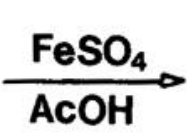

a. $\mathbf{R}=\mathbf{M e} \quad 38 \%$

b. $\mathbf{R}=\mathbf{E} \mathbf{t} \quad 28$

c. $\mathbf{R}=\mathbf{P h}$<smiles>[R]C1CCCC2CCC(C)C12</smiles>

2<smiles>CC1CCC2CCOC(=O)C12</smiles>

3

$30 \%$

18

7
$+$<smiles>C=CCCC1CCCC(=O)C1</smiles>

4

$8 \%$

17

30

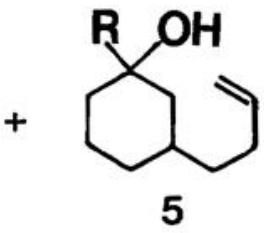

5

$18 \%$

20

7

Scheme 2 .

For example, by decomposition of l-methyl-3-(3-butenyl)cyclohexyl hydroperoxide la by ferrous ion 5-(3-methylcyclopentyl)-pentan-2-one 2a (38\%) and methyl (2-methyl 5 -n-propyl)-cyclopentyl ketone $\underline{3 a}(30 \%)$ were obtained as a products of ring reconstruction reactions.

Tertiary l-alkylcycloalkyloxy radicals, regardless of its precursors, undergo to the $\beta$-cleavage reaction and 5-carbonvlpentyl radical was formed as an intermediate ${ }^{4-6}$. By possessing an alkenyl group in position 3 of cyclohexane ring the alkoxy radical 6 is not symmetrical and two possibilities for $C_{\alpha}-C_{\beta}$ bond scission exist, thus tuo fragmented carbon centered radicals $\underline{7}$ and $\underline{8}$ were generated as intermediates (Scheme 3.). Ratio of ketones $\underline{2}$ and $\underline{3}$, derived from fragmented carbon

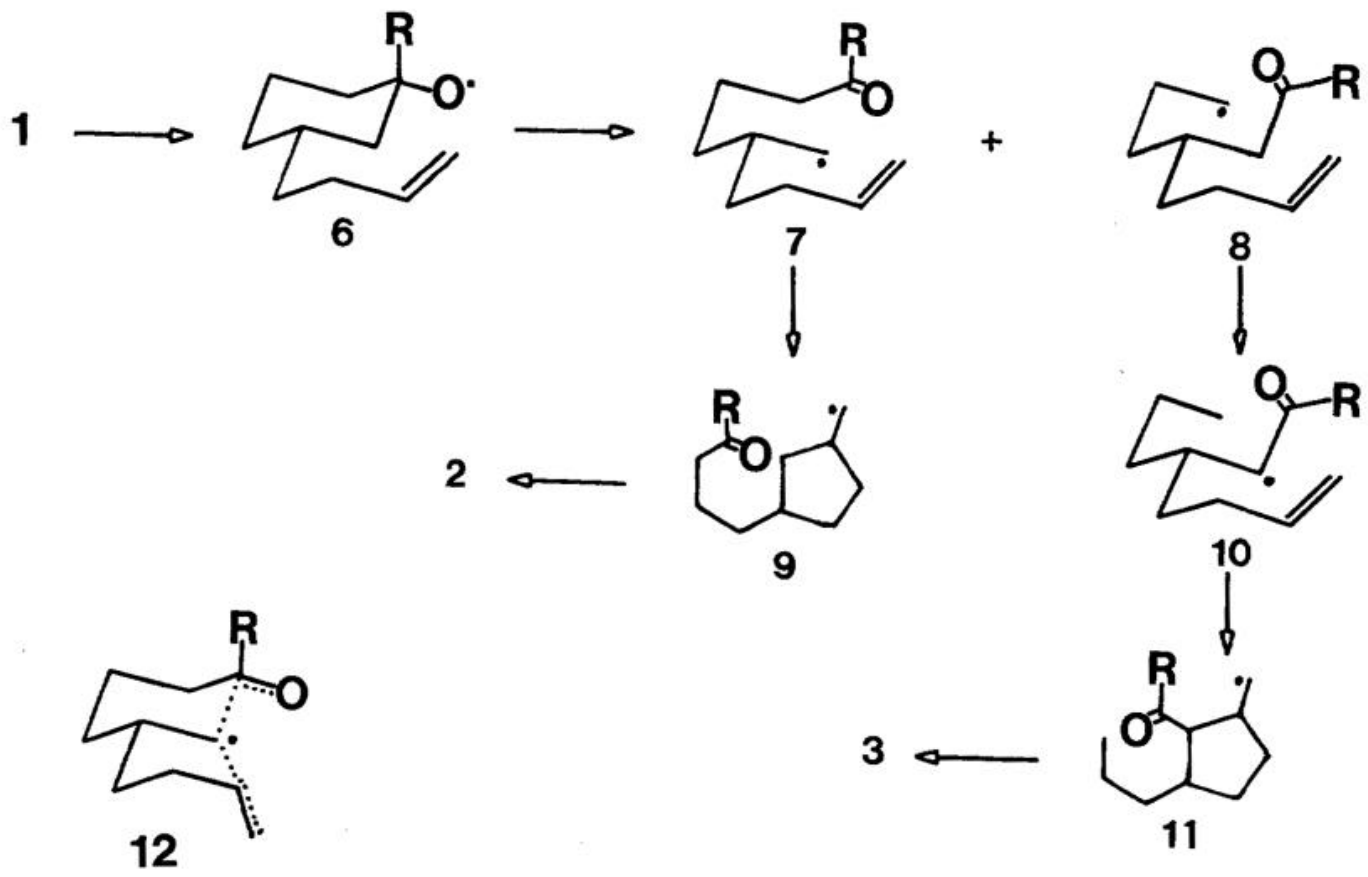


radicals $\underline{7}$ and $\underline{\hat{B}}$, respectively, indicates that a small long ringe participation of olefinic double bond on the course of $\boldsymbol{\beta}$-cleavage reaction exists. Participation of olefinic bond on the roursc of $\boldsymbol{\beta}$-scission reaction wan be explained by involving transition state 1?. Although, a litle lower yields of ketone 3 in respect to ketone 2 may be due to side reactions of radicals $\underline{8}$, 19 and 11 .

The further reaction of these two primary, fragmented, carbon radicals 7 and 8 are considerébly differert. By possessing an olefinic bond in position 5 radical 7 undergoes almost exclusively to the intramolecular 5-exo-trigonal oyclization, thus producing a cyclopentylmethyl radical g. Termination process for radical 9 is hydrogen abstraction and ketone 2 was formed as a final product of radical recombination reactions. Products of 5-endu-trigonal cyclization, caupling dicarboryl compounds and hydrogen abstraction products, which could be derived from fragmented radical $\underline{7}$, were not observed.

However, fragmented primary carbon radical $\underline{8}$ urdergoes to the $1,5-b y d-$ rogen abstraction from the methylene group adjacent to carbonyl group and a secondary radical 10 was senerated (Scheme 3.). This radical rearrangement. j.s energetically favourable for about $6 \mathrm{kcal} / \mathrm{mole} \mathrm{l}^{4}$. The fate of $\alpha-c a r b o n y l$ radical 10 with an nlefinic bond in position 5, as it was expected, it undergoes to the intramolecular cyclization reaction and a new cyclopentylmethyl radical ll arising which affords a ketone 3 as a final product ${ }^{15}$.

Saiurated ketone 2 was obtained as a pure cis-isomer, what, is in agreement with greater atability of cis-l,3-dialkylcyclopentane derivatives 16 , as well as more favourable conîrmation of butenyl group in carbor radical $7 p$ ( $5 c h e m e 4$. ), with quasi-endo-orientation of olefinic bond leading to cis-isomer 2 . While the

\section{cis-2}

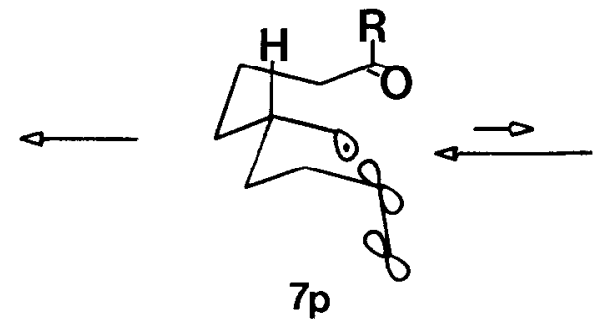

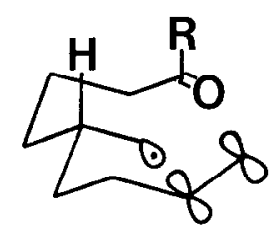

$7 q$

Scheme 4 .

conformation $7 \mathrm{q}$ which is requested for trans-isomer formation with quasi-exo-orientation of alkenyl group is lesa fávourable.

Investigation of other type of alkoxy radical precirsors and other type of rings reconstructions are in progress.

References and Notes

1. P. Cray and A. Williams, Chem. Rev., 59, 239 (1959); C. Walling and A. Padwa, I. Am* Chem. Soc., 83, 1592 (1963); C. Walling and B. B. Jacknow, J. Am Chem. Soc., 82, 6108 (1960); F. D. Greene, M. L. Savitz, F. D. Osterholtz, H. H. Lau, W. N. Smith and P. M. Zanet, J. org. Chem., 28, 55 (1963).

2. J. K. Kochi in Free Radicals, Ed. by J. K. Kochi, Vol. 2, Ch. 23, pp 683, Wiley Intersciences, New York, 1973 ; J. D. Bacha and J. K. Kochi, J. Org. Chem., 30, $3272(1965)$. 
3. M. Lj. Mihailović and Ž. Čeković, Synthesis, 209 (1970); M. Lj. Mihailović, Ž. Čeković, Lj. Loreng, in Organic Synthesis by oxidatinn with Metal Compounds, Ed. by W. J. Mijs and C. R. H. I. de Tonge, Ch. 14, pp 772, Plenum Press, New York, 1986 ; K. Heusler and J. Kalvoda, Angew. Chem., Internat. Ed., 3 , 525 (1964); Ž. Čeković and G. Djokić, Tetrahedron, 37 , 4263 (1981).

4. G. Sosnovsky and D. J. Rawlinson, in Organic Peroxides, Ed. by D. Swern, Vol. 2 Ch. 2, Wiley Intersciences, New York, 1971; D. H. Hey, C. J. M. St1rling and G. H. Williams, J. Chem. Soc., 1054 (1957); S. Choe and S. Tsutsumi, Nippon Kagaku Zasshi, 82,52 (1961), Chem. Abstr. 56, 14096 (1962).

5. P. Kabasakalian and E. R. Townley, J. Org. Chem., 27, 2918 (1962); F. Minisci, M. Cecera, R. Galli and R. Bernard1, Tetrahedron, 2ㅍ, 2667 (1969).

6. G. I. Nikishin, N. I. Papustina, S. S. Spektor and E. I. Kaplan, Izv. Akad. Nauk SSSR, Ser. Him., 1548, 2383 (1979).

7. C. Walling, J. H. Cooley, A. R. Ponars and E. J. Racah, J.Am. Chem. Soc., 88, 5361 (1966); A. L. J. Beckwith and K. U. Ingold, Free Radical Rearrangement, in Reareangement in Ground and Excited States, Vol. 1. Academic Press Inc., New York 1980; A. L. J. Beckwit, Tetrahedron, 37, 3073 (1981); A. L. J. Beckwith and C. H Schiesser, Tetrahedron, 41, 3925 (1985).

8. J. -M. Surzur, in Reactive Intermediates, Ed, by A. A. Abramovich, Vo1. 2. Ch. 3 Plenum Press, New York, 1981; S. $-K$. Chung and M. Newcomb, J.Am. Chem. Soc., 108 240 (1986); E. J. Corey and S. G. Pyne, Tetrahedron Letters, 24, 2821 (1983).

9. J. Wilt, Tetrahedron, 41, 3979 (1985); Y. Ueno, M. Chino and M. Okawa, Tetrahedron Letters, 23, 2575 (1982); J. -K. Choi and D. J. Hart, Tetrahedron, 41, 3959 (1989)

10. Prepared by reaction of alcohols $\underline{5 a}-\underline{c}$ with concentrated hydrogen peroxide ( $80 \%)$ and catalytic amount of sulfuric acid. Purity of alkyl hydroperoxides were from 88-95\%. N. A. Milas and L. H. Perry, J. Am. Chem. Soc., 68, 1938 (1946); R. Criegee and H. Dietrich, Ann., 560, 135 (1948).

11. Mixtures of isomeric alkylhydroperoxides were used.

12. Ž. Čeković, Lj. Dimitrijević, G. Djokić and T. Srnić, Tetrahedron, 35, 2021 (1979) ž. Čeković and Lj. Dimitrijević, Glasiik Hem. društva Beograd, 46, 79 (1981).

13. Yields were calculated in respect to the $88-95 \%$ purity of starting alkyl hydroperoxides $\underline{1} \underline{a}-\underline{c}$.

14. K. D. King, D. M. Golden and S. W. Benson, J.Am. Chem. Soc., 92, 5541 (1970); J. Grzechowiak, J. A. Kerr and H. F. Trotman-Dickenson, J. Chem. Soc., 5080 (1969) R. K. Solly, D. M. Golden and S. W. Benson, Int. J. Chem. Kinet., 2, 11 (1970).

15. Intramolecular additions of carbon radicals bearing an electron-withdrawing group on the adjacent carbon atom are described. ̌̌. Čeković and R. Saičić, submited for publication in Tetrahedron Letters and references therein.

16. J. N. Haresnape, Chem. \& Ind., 1091 (1953).

(Received in UK 10 October 1986) 